\title{
CHEMILUMINESCENCE OF HUMAN LEUKOCYTES STIMULATED BY CLINICAL ISOLATES OF KLEBSIELLA
}

\author{
A. M. Simoons-Smit, A. M. J. J. Verweij-van Vught, I. Y. R. Kanis and \\ D. M. MacLaren
}

Research group for Commensal Infections, Departments of Medical and Oral Microbiology, School of Medicine and Dentistry, Free University, Amsterdam, The Netherlands

\begin{abstract}
SUmMARY. Chemiluminescence (CL) of human polymorphonuclear leukocytes was determined after stimulation with 89 clinical isolates of Klebsiella which differed in serotype and in their virulence for mice. With $\mathrm{K} 1, \mathrm{~K} 2, \mathrm{~K} 4$ and $\mathrm{K} 5$ strains, a significantly lower $\mathrm{CL}$ response was observed than with $\mathrm{K} 3, \mathrm{~K} 6$ and $\mathrm{K}>6$ strains. These results correlated well with virulence: greater virulence could be explained by greater resistance to phagocytosis.
\end{abstract}

\section{INTRODUCTION}

Previous work with clinical isolates of Klebsiella showed that serotypes differed in their virulence for mice (Simoons-Smit et al., 1984). K1 and K5 strains, and most K2 and $\mathrm{K} 4$, were more virulent for mice than $\mathrm{K} 6$ and serotypes higher than $\mathrm{K} 6$, whereas K3 strains were significantly less virulent. A factor which may contribute to their virulence is the degree of resistance to host defence mechanisms, such as phagocytosis. For Klebsiella strains, Hall and Humphries (1958) found a close correlation between virulence (intraperitoneal LD50) and susceptibility to phagocytosis by the polymorphonuclear leukocytes (PMNL) of mice, but they tested only four strains. Association between virulence and resistance to the bactericidal activity of human granulocytes has been demonstrated for encapsulated strains of other common pathogens (Howard and Glynn, 1971; Melly et al., 1974; Rottini et al., 1975).

Allen et al. (1972) first described chemiluminescence (CL) of PMNL during phagocytosis of bacteria. This CL is the consequence of the generation of electronically exited oxidative radicals by the metabolic burst, and can be enhanced by the addition of luminol (5-amino 2,3-dihydrophthalazinedione) to the phagocytosis system (Allen and Loose, 1976). Many authors have shown a correlation between this luminolenhanced CL and phagocytosis (Grebner et al., 1977; Stevens and Young, 1977; Welch and Stevens, 1979; Ewetz et al., 1979; Williams et al., 1980). CL response is, therefore, used indirectly to quantitate phagocytosis.

In this study luminol-enhanced CL of human leukocytes was determined after stimulation by various serotypes of Klebsiella, to investigate any correlation between resistance to phagocytosis, measured by $\mathrm{CL}$, and virulence for mice. 


\section{MATERIALS AND METHODS}

Bacterial strains. Of the 93 Klebsiella strains described previously (Simoons-Smit et al., 1984), 89 strains were used in this study (see table). The strains were identified to species level by API-20E (API-system S.A., Montalieu-Vercieu, France) in which system $K$. pneumoniae includes all Klebsiella biotypes not in the species $K$. rhinoscleromatis, $K$. ozaenae and $K$. oxytoca. They were serotyped by the capsule-swelling technique with rabbit antisera. Strains with a serotype higher than $\mathrm{K} 6$, including five non-typable strains, are referred to as $\mathrm{K}>6$ strains.

Bacterial suspensions. Log-phase cultures of strains in nutrient broth were harvested by centrifugation, and resuspended in phosphate-buffered saline (PBS). Viable counts of these suspensions were determined by plating serial dilutions on nutrient agar. After storage overnight at $4{ }^{\circ} \mathrm{C}$ the suspensions were diluted to $c .10^{8}$ bacteria $/ \mathrm{ml}$, and these concentrations were confirmed retrospectively by viable counts.

Zymosan (Sigma Chemical Co., St Louis, USA) $4 \mathrm{mg}$ was suspended in $2 \mathrm{ml}$ of PBS and heated for $30 \mathrm{~min}$ at $100^{\circ} \mathrm{C}$ in a waterbath. The suspension was washed twice in PBS after which the pellet was suspended in PBS to a concentration of $0.8 \mathrm{mg} / \mathrm{ml}$. This Zymosan suspension was stored in small volumes at $-20^{\circ} \mathrm{C}$ and diluted 1 in 10 before $\mathrm{CL}$ experiments.

Serum. Pooled normal human serum from $c .50$ healthy individuals was stored in small volumes at $-70^{\circ} \mathrm{C}$ and used throughout all experiments at a final concentration of $10 \% \mathrm{v} / \mathrm{v}$.

Preparation of polymorphonuclear leukocytes. Venous blood was obtained from healthy donors, with heparin (14 units $/ \mathrm{ml}$ ) as anticoagulant. After mixing five parts of the blood with one

TABLE

Klebsiella strains

\begin{tabular}{|c|c|c|}
\hline Serotype & Species* & Number of strains (89) \\
\hline K1 & K. pneumoniae & 9 \\
\hline $\mathrm{K} 2$ & K. pneumoniae & 9 \\
\hline K3 & K. pneumoniae & 5 \\
\hline K3 & K. oxytoca & 6 \\
\hline K3 & K. rhinoscleromatis & 1 \\
\hline K4 & K. ozaenae & 8 \\
\hline $\mathrm{K} 4$ & $K$. pneumoniae & 1 \\
\hline K5 & K. pneumoniae & 3 \\
\hline K5 & K. pneumoniae (NCTC 9660) & 1 \\
\hline K6 & K. pneumoniae & 5 \\
\hline K7 & K. pneumoniae & 1 \\
\hline K8 & K. pneumoniae & 1 \\
\hline K10 & K. pneumoniae & 1 \\
\hline K 18 & K. pneumoniae & 3 \\
\hline $\mathrm{K} 21$ & K. pneumoniae & 4 \\
\hline $\mathrm{K} 24$ & K. pneumoniae & 1 \\
\hline $\mathrm{K} 26$ & K. oxytoca & 1 \\
\hline $\mathrm{K} 27$ & $K$. pneumoniae & 3 \\
\hline $\mathrm{K} 27$ & K. oxytoca & 1 \\
\hline K 29 & K. oxytoca & 1 \\
\hline K33 & K. pneumoniae & 5 \\
\hline K 35 & K. pneumoniae & 2 \\
\hline $\mathrm{K} 43$ & K. pneumoniae & 2 \\
\hline $\mathrm{K} 55$ & $K$. oxytoca & 2 \\
\hline $\mathrm{K} 61 / 63 / 10^{\dagger}$ & K. pneumoniae & 1 \\
\hline $\mathrm{K} 61 / 63 / 10^{\dagger}$ & K. oxytoca & 1 \\
\hline K64 & K. pneumoniae & 2 \\
\hline K69 & K. oxytoca & 4 \\
\hline NT & K. pneumoniae & 5 \\
\hline
\end{tabular}

NT $=$ non-typable

* In contrast with the identifications in our previous study (Simmons-Smit et al., 1984) API-20E now classifies as $K$. oxytoca the indole-positive biotypes of $K$. pneumoniae.

$\dagger$ Reacted with all three antisera. 
part of dextran $6 \% \mathrm{w} / \mathrm{v}$ in PBS, the erythrocytes were allowed to sediment for 30 min at $37^{\circ} \mathrm{C}$. The leukocyte-rich plasma was centrifuged at $250 \mathrm{~g}$ for $5 \mathrm{~min}$ at $4^{\circ} \mathrm{C}$. To the pellet was added $5 \mathrm{ml}$ of a solution of $\mathrm{NH}_{4} \mathrm{Cl} \mathrm{g}, \mathrm{KHCO}_{3} 1 \mathrm{~g}$, and disodiumethylenediamine-tetra-acetic acid $37 \mathrm{mg}$, per litre of sterile distilled water. After $10 \mathrm{~min}$, to allow lysis of residual erythrocytes, the leukocytes were centrifuged, washed twice in Hanks's medium (Gibco, Paisley, UK) containing gelatin $0 \cdot 1 \%$, and resuspended in the same medium to give $5 \times 10^{6}$ leukocytes $/ \mathrm{ml}$.

Measurement of chemiluminescence. The reaction mixture consisted of: $0 \cdot 1 \mathrm{ml}$ of the leukocyte suspension $\left(5 \times 10^{6} / \mathrm{ml}\right), 0 \cdot 1 \mathrm{ml}$ of a bacterial suspension $\left(10^{8} / \mathrm{ml}\right), 0 \cdot 1 \mathrm{ml}$ of pooled normal serum $(40 \% \mathrm{v} / \mathrm{v})$ and $0.1 \mathrm{ml}$ of $0.1 \mathrm{~mm}$ luminol (Lumac Systems A.G., Basel, Switzerland) in PBS, giving a bacteria: leukocyte ratio of 20:1. The mixtures were incubated in Lumacuvette P-tubes in a shaking waterbath at $37^{\circ} \mathrm{C}$. CL was measured every $10 \mathrm{~min}$ up to $60 \mathrm{~min}$ in a Lumacounter ${ }^{\circledR}$ M2080 (Lumac Systems A.G., Basel, Switzerland) in the integral mode with a preset of $10 \mathrm{~s}$; and the mean of counts during five periods of $2 \mathrm{~s}$ each was recorded on a HP model $97 \mathrm{~S}$ microcomputer (Hewlett Packard, Corvallis, USA). After curve-area integration, this CL response was expressed as a percentage of the curve-area integration obtained when the bacterial suspension was replaced with the standardised Zymosan suspension in the same reaction mixture.

\section{RESULTS}

Typical CL patterns of a virulent strain (K5), avirulent strains (K6 and K69) and the Zymosan suspension are shown in fig. 1. CL was low immediately after mixing, and it increased during the first $10 \mathrm{~min}$; peak CL counts occurred mostly after $20-30 \mathrm{~min}$.

To compare the CL response of PMNL stimulated with different strains, and performed with leukocyte suspensions of different donors on different days, we included the standardised Zymosan suspension in all experiments. The mean

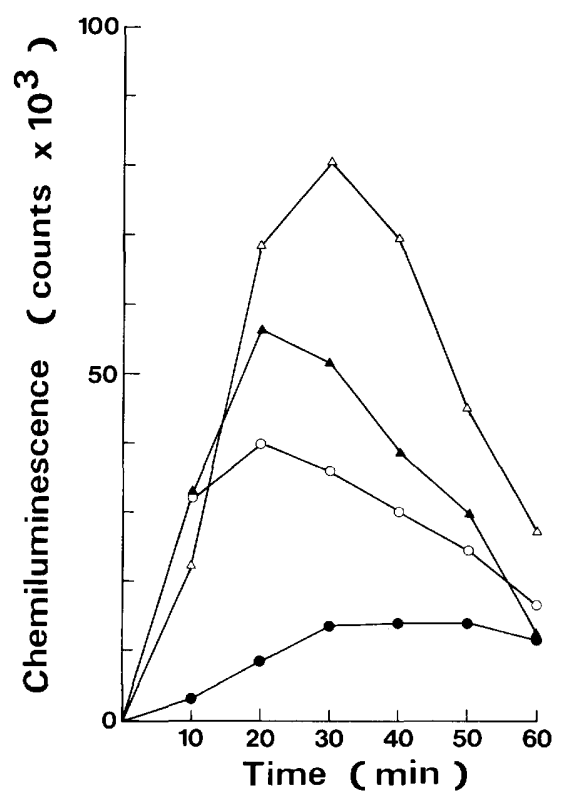

FIG. 1.-Kinetics of chemiluminescence of PMNL activated by Klebsiella K $5(\bullet-\bullet), \mathrm{K} 6(\Delta-\mathbf{\Delta}), \mathrm{K} 69$ $(\Delta-\Delta)$ and a standardized Zymosan suspension $(\mathrm{O}-\mathrm{O})$. 


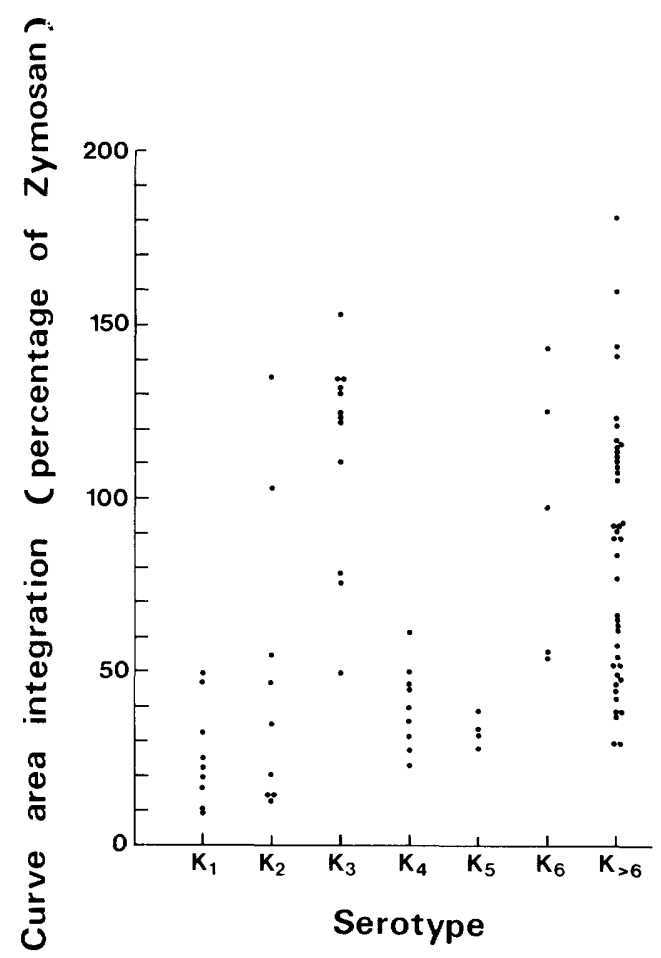

FIG.2.-CL response of PMNL towards different serotypes of Klebsiella strains (curve-area integration expressed as a percentage of the curve-area integration of a standardised Zymosan suspension.)

curve-area integration of the CL response caused by Zymosan was $2 \cdot 08 \times 10^{6}$, with a standard deviation of $0.90 \times 10^{6}(43 \%)$. Despite this rather high variation with Zymosan between different experiments, the CL response (curve-area integration) caused by bacterial suspensions, expressed as a percentage of the curve-area integration of Zymosan tested on the same occasion, was reproducible.

Fig. 2 shows the CL responses of PMNL towards different Klebsiella isolates, calculated as described above. Each point is the mean $\mathrm{CL}$ value of at least two experiments with one strain, obtained with different leukocyte suspensions on different days. All $\mathrm{K} 1$ and $\mathrm{K} 5$ strains and nearly all $\mathrm{K} 2$ and $\mathrm{K} 4$ strains gave a low CL response, whereas nearly all $\mathrm{K} 3, \mathrm{~K} 6$ and $\mathrm{K}>6$ strains gave a higher $\mathrm{CL}$ response.

Statistical analysis by the Wilcoxon test, at a significane level of $\mathrm{p}=0 \cdot 01$, showed that the $\mathrm{CL}$ response of the $\mathrm{K} 1, \mathrm{~K} 2, \mathrm{~K} 4$ and $\mathrm{K} 5$ strains differed from that of the $\mathrm{K}>6$ strains, whereas that of the K6 strains did not ( $p>0.05)$; 33 strains differed from $K>6$ strains at a significance level of $\mathrm{p}=0.05$.

The CL response of PMNL, stimulated with different strains, was enhanced by the presence of serum in the reaction mixture. Without serum, the CL response caused by 36 strains was $5-34 \%$ (mean $14 \%$ ) of the CL response with the same strains tested in $10 \%$ serum. In a few experiments with serum inactivated for $30 \mathrm{~min}$ at $56^{\circ} \mathrm{C}$, the $\mathrm{CL}$ responses were at the same low level as, or somewhat higher than, those obtained without serum. 


\section{DisCUSSION}

Clinical isolates of Klebsiella were able to stimulate human PMNL in the presence of serum. The measurement of the resulting CL was facilitated by the reducing agent, luminol. The lowest CL response was observed with all $\mathrm{K} 1$ and $\mathrm{K} 5$ strains and nearly all $\mathrm{K} 2$ and $\mathrm{K} 4$ strains, whereas the $\mathrm{CL}$ response of nearly all $\mathrm{K} 3, \mathrm{~K} 6$ and $\mathrm{K}>6$ strains was higher and showed a wider scatter. The low CL response with $\mathrm{K} 1, \mathrm{~K} 2, \mathrm{~K} 4$ and $\mathrm{K} 5$ correlates with their virulence for mice (Simoons-Smit et al., 1984). In skin pathogenicity, $\mathrm{K} 1, \mathrm{~K} 2, \mathrm{~K} 4$ and $\mathrm{K} 5$ were significantly more virulent than $\mathrm{K} 3, \mathrm{~K} 6$ and $\mathrm{K}>6$. The good correlation between the $\mathrm{CL}$ response of human PMNL and the virulence of the same strains in mice is demonstrated by the calculated correlation coefficient $r=-0.9175$ for the mean of the values for CL and for virulence with each group of strains (K1, K2, K3, K4, K5, K6 and $\mathrm{K}>6$ ).

$\mathrm{CL}$ reflects the metabolic activity of leukocytes during phagocytosis (Cheson et al., 1976; Schadelin et al., 1981), and is often used as an indirect measure of phagocytosis. The necessity of an intact complement system and other factors like immunoglobulins to obtain an optimal CL response, was demonstrated by the low CL responses with 36 strains tested without serum and a few strains tested with complement-inactivated serum. These observation reject the role of random adherence of bacteria to human PMNL, independent of the phagocytic process, as the source of the CL response.

Our results indicate that $\mathrm{K} 1, \mathrm{~K} 2, \mathrm{~K} 4$ and $\mathrm{K} 5$ strains were more resistant to phagocytosis than $\mathrm{K} 3, \mathrm{~K} 6$ and $\mathrm{K}>6$ strains. The in-vitro resistance to phagocytosis might explain the greater virulence of these strains for mice, if we assume a low rate of phagocytosis in vivo too. The observation that strains virulent in the mouse are poorly phagocytosed by human PMNL, and vice versa, suggests that the mouse model may be useful in evaluating the virulence of Klebsiella strains in man.

The overall correspondence of certain $\mathrm{K}$ types with high virulence and high resistance to phagocytosis clearly illustrates the importance of certain $\mathrm{K}$ antigens in virulence of Klebsiella. However, not all strains fit into this scheme. Single strains of some serotypes of $\mathrm{K}>6$ with low virulence for mice (fig. 2) gave a CL response as low as with most virulent strains $(\mathrm{K} 1, \mathrm{~K} 2, \mathrm{~K} 4$ or $\mathrm{K} 5)$. This overlap indicates that resistance to phagocytosis is not always the decisive determinant in pathogenicity. The ultimate evidence for the role of $\mathrm{K}$ antigens in virulence and resistance to phagocytosis will be investigated with variants of the virulent strains, devoid of $\mathrm{K}$ antigen.

This research was supported by a grant from the Praeventiefonds, 's Gravenhage, number 28-712.

\section{REFERENCES}

Allen R C, Stjernholm R L, Steele R H 1972 Evidence for the generation of an electronic exitation state(s) in human polymorphonuclear leukocytes and its participation in bacterial activity. Biochemical and Biophysical Research Communications 47:679-684.

Allen R C, Loose L D 1976 Phagocytic activation of a luminol-dependent chemiluminescence in rabbit alveolar and peritoneal macrophages. Biochemical and Biophysical Research Communications 69:245-252.

Cheson B D, Christensen R L, Sperling R, Kohler B E, Babior B M 1976 The origin of the chemiluminescence of phagocytosing granulocytes. Journal of Clinical Investigation 58:789-796. 
Ewetz L, Palmblad J, Thore A 1979 Quantitation of phagocytosis by luminol chemiluminescence. In: Schram E, Stanley P (eds) Proceedings of an international symposium on analytical applications of bioluminescence and chemiluminescence. State Printing and Publishing Inc., Westgate Village, CA, pp 582-588.

Grebner J V, Mills E L, Gray B H, Quie P G 1977 Comparison of phagocytic and chemiluminescence response of human polymorphonuclear neutrophils. Journal of Laboratory and Clinical Medicine 89:153-159.

Hall H E, Humphries J C 1958 The relationship between insusceptibility to phagocytosis and virulence of certain Klebsiella pneumoniae strains. Journal of Infectious Diseases 103:157-162.

Howard C J, Glynn A A 1971 The virulence for mice of strains of Escherichia coli related to the effects of $\mathrm{K}$ antigens on their resistance to phagocytosis and killing by complement. Immunology 20:767-777.

Melly M A, Duke L J, Liau D F, Hash J H 1974 Biological properties of the encapsulated Staphylococcus aureus M. Infection and Immunity 10:389-397.

Rottini G, Dri P, Soranzo M R, Patriarca P 1975 Correlation between phagocytic activity and metabolic response of polymorphonuclear leukocytes toward different strains of Escherichia coli. Infection and Immunity 11:417-423.

Schadelin J, Schadelin R, Mandell G L 1981 Chemiluminescence of phagocytic cells. CRC Critical Reviews in Clinical Laboratory Sciences 11:1-19.

Simoons-Smit A M, Verweij-van Vaught A M J J, Kanis I Y R, MacLaren D M 1984 Virulence of Klebsiella strains in experimentally induced skin lesions in the mouse. Journal of Medical Microbiology 17:67-77.

Stevens P, Young L S 1977 Quantitative granulocyte chemiluminescence in the rapid detection of impaired opsonization of Escherichia coli. Infection and Immunity 16:796-804.

Welch W D, Stevens P 1979 Serum requirements necessary for the opsonophagocytosis of Escherichia coli 073: K92: H1. Current Microbiology 2:245-250.

Williams A J, Hastings M J G, Easmon C S F, Cole P J 1980 Factors affecting the in vitro assessment of opsonization: a study of the kinetics of opsonization using the technique of phagocytic chemiluminescence. Immunology 41:903-911. 